\title{
Universalização da Educação Superior no Brasil: contrapontos e possibilidades
}

\section{Universalization of Higher Education in Brazil: counterpoints and possibilities}

\author{
Paulo Gomes Lima ${ }^{1}$
}

\begin{abstract}
RESUMO
O processo de universalização da Educação Superior no Brasil, mesmo em face das políticas públicas da contemporaneidade marcadas pela influência internacional, apresenta inúmeras fragilidades, dentre as quais a não problematização inclusão-exclusão, as diferenças de classe social. O presente estudo, de cunho exploratório, que utiliza as contribuições de Habermas, Mészáros, Adorno e Horkheimer e Karel Kosik para a construção de um quadro analítico, embora não tenha especificamente "a universidade" ou "políticas de ações afirmativas" como seu principal objeto de preocupação, faz com que suas contribuições se tornem significativas à medida que lançamos um outro olhar sobre as questões sociais que não podem e não devem conformarem-se ou sucumbirem à lógica pré-determinada do capital. Palavras-chave: Educação Superior; inclusão-exclusão social; universalização.
\end{abstract}

\begin{abstract}
The process of universalization of Higher Education in Brazil, even in the face of the contemporary public policies marked by international influence, features numerous weaknesses, among which are the non-problematization of inclusion-exclusion, and the social class differences. This exploratory study, which takes the contributions of Habermas, Mészáros, Adorno and Horkheimer and Karel Kosík for the construction of an analytical framework, although not having specifically "the University" or "affirmative action policies" as its main objects of concern, makes its contributions become
\end{abstract}

1 Universidade Federal de São Carlos, Campus Sorocaba, São Paulo, Brasil. Rodovia João Leme dos Santos, Km 110, Itinga - CEP: 18052-780. 
significant as we release another look on social issues that cannot and should not comply or submit to the predetermined logic of capital.

Keywords: Higher Education; social exclusion and inclusion; universalization.

\section{Introdução}

Pensar a universidade brasileira e algumas políticas públicas de inclusão, a partir de uma sociedade capitalista que se quer democrática, não pontuando as relações entre neoliberalismo, trabalho e políticas compensatórias de acesso à universidade fundantes das desigualdades e da manutenção dos arranjos históricos de exclusão é ignorar o discurso ideológico forjado por uma burguesia que ratifica sua dominação pela violência simbólica com roupagem e discurso a caráter.

Um discurso pode assumir muitos sentidos e apresentar multifacetas implícitas e explícitas, conforme a conveniência, com o objetivo de se defender uma mensagem, um conjunto de convicções para determinado grupo ou população. Numa diretriz ampla o discurso tem um sentido comum, pois diz respeito aos interesses coletivos, consequentemente centrado numa vasta ideologia. Nesse sentido, incluem-se as manifestações culturais dos grupos sociais, seu ideário difuso em nível de produção intelectual, política e econômica, bem como as perspectivas em termos de construção de metas e materialização de projetos convergentes ao bem comum (LIMA, 2005).

Noutro polo encontra-se a ideologia em sentido restrito, representante de interesses particularistas, geralmente empregada de maneira velada e, não raras vezes, naturalizada como se fosse em sentido amplo, como se materializasse em sua completude o conjunto solidário do consenso social. Encampando a roupagem de uma ideologia em sentido amplo, o metabolismo do capital, dentre outros receituários para os países em desenvolvimento, engendrou consideravelmente a naturalização de sua ideologia em sentido restrito pelo aventamento de políticas públicas de inclusão social.

Ao convidarmos para o debate autores como Habermas, Mészáros, Adorno, Horkheimer e Karel Kosik, destacamos que os seus objetos de discussão, embora não sejam especificamente "a universidade" ou as "políticas de ações afirmativas", como estamos problematizando, nos trazem contribuições significativas para entendermos que é necessário um outro posicionamento, um outro olhar sobre as questões sociais que não podem e não devem conformar-se 
ou sucumbirem à lógica pré-determinada do capital, como observaremos no desdobramento deste artigo.

\section{Alguns desafios contextuais para a universidade brasileira}

A partir da década de 1990, período em que no Brasil as políticas de inclusão educacional são mais evidentes, intensifica-se o discurso neoliberal, cuja viabilização se daria por conta da ruptura das economias nacionalistas, ratificando a internacionalização da mesma.

$\mathrm{Na}$ sociedade contemporânea, globalizada e excludente, o estudo sobre a inclusão educacional não pode ser descontextualizado da centralidade capital-trabalho (MÉSZÁROS, 2005) pelo risco da conivência com um discurso e práticas dissimuladoras produzidas pelo metabolismo social do capital.

A inclusão educacional, por meio de ações afirmativas, no caso da universidade brasileira por meio de cotas sociais, é um objeto não isento dessa centralidade, solicitando o desvelamento das contradições e complexidades, o que não imiscui e nem minimiza os conflitos e debates a respeito da luta de classes, pela identidade da cultura brasileira, e a superação de desigualdades por meio de transformação social qualitativa no seio da universidade, que problematizamos nesse ensaio.

Entendemos que a nota tônica da questão não é, como já afirmamos, colocar-se a favor, caminho que incorpora acalorados discursos no interior da universidade brasileira à luz de uma social-democracia anunciada e que encontra uma forte ecoação em movimentos sociais como rota necessária da Terceira Via (na articulação da direita, da esquerda e de todos os povos), nem mesmo reunir oposições tácitas simplesmente, como que adotando um posicionamento conservador da institucionalização histórica na universidade, que deve primar pela excelência dos serviços oferecidos à sociedade; pelo contrário, é problematizarmos a motivação do capital global que intensifica suas investidas, inclusive no âmbito de políticas sociais, tornando o seu poder muito mais legítimo do que a força e as necessidades reais dos Estados Nacionais.

Aponta Antunes (2004, p. 118): "O mundo do trabalho tem uma conformação cada vez mais mundializada" que condiciona e mobiliza intenções e ao mesmo tempo radica a expansão do capital. As políticas de inclusão social e quaisquer outros instrumentos que contribuam para esse fim serão empregados em toda a sua amplitude de forma ideológica em sentido restrito e, portanto, alienante. 
As políticas públicas compensatórias ou, nesse caso, as de ações afirmativas surgidas nos EUA e adotadas em vários outros países, como o Brasil, estão em consonância com essa lógica capitalista, isto é, são elaboradas, desenvolvidas e implementadas pelo Estado para conter ou minimizar as "distorções sociais", não no sentido de promoção da justiça social universalizada, mas num arranjo de desmobilização de solicitações coletivas.

Estabelecidos os pressupostos representativos, pressupõe-se que a dívida histórica esteja paga, mesmo que um contingente significativo de pessoas seja destituído da situada oportunidade, ao mesmo tempo em que são desviados os eixos de discussão acerca de uma sociedade democratizadora e democratizante em sentido universalizado e ratificado o compromisso com a construção de perfil de homem universal sim, mas para uma sociedade determinada: a capitalista, promotora de mercados e cidadãos consumidores.

Dentre as políticas compensatórias, para efeitos do nosso objeto, destacam-se as políticas de cotas para acesso à universidade de grupos socialmente desfavorecidos, no caso do Brasil, de negros, indígenas e pobres.

O maior desafio da universidade está na atitude, como instituição social, de despertar e fazer despertar uma outra consciência, não num plano utópico, mas da leitura das recorrências sociais não excludentes, da vida para a vida. Marx e Engels (1987, p. 25-26) vão afirmar que a "produção de idéias, de representações e da consciência está em primeiro lugar direta e intimamente ligada à atividade material e ao comércio material dos homens; é a linguagem da vida real [...] Não é a consciência que determina a vida, mas a vida que determina a consciência."

Dessa construção, as ideias produzidas pelo aparelho de Estado precisam ser contextualizadas, as intencionalidades questionadas na medida em que a atuação do homem sobre o mundo vivido constitua-se na organização do conhecimento e intervenções pertinentes, como produto de múltiplas determinações. Esse é o maior desafio, dado que todos os organismos na relação capital-trabalho reforçam o inverso.

Recuperar o sentido da consciência coletiva como resposta ao processo de expropriação de direitos sociais, dentre os quais o da Educação Superior numa dimensão universalizada, é uma tarefa em construção que não pode ser deixada em segundo plano e nem negociada por medidas paliativas que pretendem, em nome da "minimização de distorções sociais", conservar a estrutura capitalista do controle social de mentes e corpos.

E o que não dizer da expropriação velada dos direitos do homem sobre a constituição de sua humanização como sujeito histórico que por conta dessa perda da coletividade vem se tornando um autômato programado, cuja verdade "autorizada" é embalada pela lógica individualista do metabolismo do capital, 
cerceadora do desdobramento de uma consciência coletiva autônoma, porque essa poderia comprometer o seu ideário?

Essa consciência coletiva aprimora os relacionamentos na consecução de objetivos comuns, pois coloca como ponto de partida a participação de todos os atores sociais envolvidos com a universidade e seu entorno e todos os interesses sociais numa dimensão universal, humanizadora e democrática, pois, como afirma Antunes (2004, p. 118), "A luta contra o domínio do capital deve articular luta social e luta política num complexo indissociável."

Assim, a consciência que emancipa, gerada num espaço democrático, em que os sujeitos sentem-se parte indissociável da história na e da tomada de decisão sobre o seu destino, pode provocar uma cisão radical com a teoria social do capitalismo. Consequentemente, nessa disposição, as solicitações são analisadas em profundidade e a participação se materializa por meio do exercício do direito de vez, voz e voto.

É a partir da consciência coletiva que surgem e são encaminhados questionamentos acerca de uma outra sociedade que entende justiça social não como consentimento ou espaço de inclusão, mas como espaço da não exclusão em todo e qualquer grau, do não antagonismo na redistribuição de renda, do direito à terra e à categoria mais importante, a humanização em seu sentido mais amplo.

Para isso algumas indagações devem ser sempre evidentes: Quem somos? Onde estamos e qual é a finalidade do desenvolvimento do nosso trabalho material e imaterial? Como aperfeiçoar a nossa ação interventiva de forma a promover a melhoria de qualidade do que produzimos sem ferir e expropriar o direito universal dos demais? Como nos posicionamos politicamente frente às crises do mundo contemporâneo e por meio de seus condicionantes provocamos a crítica reflexiva? Em que grau e em que medida a universidade contribui efetivamente para a emancipação do indivíduo e para o exercício pleno de sua cidadania?

$\mathrm{Na}$ contemporaneidade não há como não observar a materialização desse itinerário, bem como as políticas públicas derivadas de organismos multilaterais para os países em desenvolvimento, assumidas como fruto de uma articulação solidária dos direitos do homem, que lhe conferem a dimensão mais completa que já houve quanto à democratização, à humanização e à universalização.

Ao pensarmos o arranjo social e econômico do mundo capitalista, qual é, de fato, a possibilidade de pensarmos uma educação solidária em sentido amplo, uma educação que não faça o homem lobo do próprio homem? No caso da universidade brasileira, como já afirmamos, por mais que seja solidária e disposta a desenvolver políticas compensatórias para a correção de dívidas históricas no seu interior, o seu alcance é pontual, uma vez que não foi delineada para todos.

Ela serve, portanto, no arranjo em que se apresenta, como moeda de troca de uma sociedade de classes continuamente excludente, vendendo a imagem de 
inclusão social, convencendo sobre a sua efetividade e desmobilizando qualquer possibilidade de transformação numa dimensão universal, democrática e humanizadora.

Tal dimensão requer uma discussão problematizada em quatro eixos que clarifiquem dialeticamente um terceiro olhar sobre as proposições das ações afirmativas para a universidade brasileira, excluído convenientemente da previsibilidade da teoria do metabolismo do capital, por evidenciar suas tramas e fragilizar sua aceitação tácita, tornando a construção social um produto comum e banalizado.

Esse itinerário faz a denúncia do jogo de expropriação do homem pelo capital, que reduz e utiliza o direito pela e para a naturalização do âmbito particular em relação ao universal. Um terceiro olhar sobre a lógica das políticas públicas internacionalizadas não propõe uma concreticidade do mundo a partir de uma sinergia doutrinária que oculta o verdadeiro sentido e intencionalidade dos grupos hegemônicos, o que comumente se faz e se espera dentre favoráveis e contrários às postulações neoliberais, mas evoca uma postura, um chamamento para a mobilização expressiva contrária à lógica de uma inclusão social forjada à universidade.

\section{Dimensão universal e democrática da universidade: possibilidades?}

A consideração de uma dimensão universal, democrática e humanizadora não admite o confinamento conceitual do sentido de democratização do acesso à universidade, dado que a democracia só pode ser exercida de forma ampla e irrestrita numa práxis comunitária (HABERMAS, 2007).

Nesse sentido, o direito não pode ser prescrito por uma ideia forjada de soberania popular ou a partir de uma responsabilização solidária, quando às custas do direito propriamente dito se propala a inclusão social e se restringe, à luz de medidas pseudocorretivas, a materialização da sua validade equitativa. Para a problematização da ação comunicativa promotora do âmbito emancipador do sujeito histórico, considerando em nossa interlocução o direito cidadão aos bens comuns, optamos por fazê-lo como primeiro eixo, por meio de Jürgen Habermas (2003a, 2003b, 2007).

A divisão social de classes e o arranjo naturalizado da expropriação que diz respeito ao homem, do produto de seu trabalho pelo capital, erigem valores, estabelecem códigos morais e ratificam a conformação humana aos parâmetros éticos de sua estrutura. Todas as condições, problemas de cunho infraestrutural 
e horizontalização do direito e produto do trabalho são considerados em âmbitos particularizados ou setorializados - tratamento tecnicista e pontual que os Estados capitalistas determinam como soluções necessárias para o seu exercício e funcionamento.

As políticas públicas são estruturadas a partir da ênfase para a conservação do controle social considerando-se a economia mundializada e os ideários que as sustentam; logo, cria-se a exigência da construção de imaginários sociais que as respaldam, apresentando, de forma mítica, "o esclarecimento necessário" sobre as medidas anunciadas "universalizantes", quando de fato os interesses particularistas prevalecem. O segundo eixo de discussão problematiza, a partir de Adorno e Horkheimer (1985, 1973), essa disposição antagônica entre o particular e o universal.

A orientação da divisão internacional do trabalho pela imposição e determinação do imaginário social estabelece os papéis definidos entre países desenvolvidos e em desenvolvimento mediante uma racionalidade instrumental que convoca à responsabilização solidária: empenho e inserção de políticas inclusivas, erradicação da pobreza e, para isso, forte ênfase na educação, centrada nos mesmos indicadores do mercado: eficiência, eficácia e produtividade.

Há a apresentação de um mundo pseudoconcreto cuja leitura linear divulga a diversidade, mas uniformiza o âmbito material e conceitual da mesma; que anuncia a solidariedade no enfrentamento dos desafios sociais, políticos e econômicos dos países pobres, entretanto, radicando o fortalecimento dos conteúdos do metabolismo do capital com ações simplesmente pontuadas, ocultadoras das intencionalidades e da mobilização conveniente à globalização produtiva e que discursa e implementa processos, anunciados de um governo descentralizador, mas que de fato contribui para o afinamento com a esfera privada, que no caso desse ensaio tem nas universidades privadas o seu principal representante. $\mathrm{O}$ aprofundamento dessa problematização será efetuado por meio de Kosik (1976), como terceiro eixo, que provoca a leitura da realidade por meio da concreticidade dialética.

E como quarto pilar de discussão, por meio da desocultação das práticas dissimuladoras na centralidade capital-trabalho, propomos, a partir de Mészáros (2004, 2005, 2006a, 2006b, 2007 e 2009), um encaminhamento concreto para a construção de uma universidade, na dimensão democrática, humanizadora e universal, por meio da necessária exigência da superação da lógica do capital que desumaniza o homem e nega essa ação, promove o individualismo e busca seus fundamentos no lucro e na competição.

A questão que orienta a discussão desse eixo e do trabalho como um todo se debruça sobre a possibilidade de se construir uma educação ou uma universidade não excludente, promotora de direitos em sentido democrático e humanizadora 
na reflexão e transformação das necessidades sociais, políticas, econômicas e culturais em objetos, de fato, concretos. Mészáros (2005), a esse respeito, afirma que se faz necessário resgatar o sentido estruturante da educação, a começar pela aniquilação da separação entre Homo faber e Homo sapiens, uma vez que a educação não se explica a partir de si mesma, pois "[...] tem de sair às ruas, para os espaços públicos e se abrir para o mundo.” (p. 10).

Os interesses sociais, no âmbito da democratização do ensino superior, não podem prescindir desse olhar, não podem se encerrar na descrição e oferta de oportunidades de um metabolismo social ideologicamente forjado. As pontuações que fizemos a partir de cada um dos eixos, apresentados a seguir, contribuem em sua totalidade para a problematização e encaminhamento da universidade nas dimensões democrática, humanizadora e universal, não como proposição utópica, mas como realidade necessária à superação do metabolismo do capital.

\section{A universidade e o agir comunicativo do direito na determinação da ação histórica em Habermas}

Se o procedimento democrático fundamenta a legitimidade do direito (HABERMAS, 2003a, 2003b), certamente podemos inferir que a legitimidade do direito deve assegurar o procedimento democrático. No caso, as categorias direito e democracia devem estar intrinsecamente relacionadas em todo momento, a ponto de assegurar a universalização e participação do que se conhece como oportunidades necessárias e igualitárias da vida social.

A ação social comunicativa em nível democrático, universal e humano, promotora e garantidora da equidade propriamente dita, não pode aceitar medidas pseudocorretivas que prometem a justiça social e circunscrevem o seu cumprimento a partir do direito e simultaneamente apresentam uma caricatura de cidadania e de espírito democrático, conforme interesses particularistas.

Se de fato fosse materializada a equidade de maneira universalizada, como aponta Habermas, não haveria discriminação em suas distintas manifestações e nem medidas paliativas seriam aceitas, considerando a integridade do direito cidadão em toda a sua extensão. Mas como se sabe, "as liberdades iguais" são circunscritas pela natureza das desigualdades de classe e pela divisão social do trabalho e, consequentemente, pelo poder aquisitivo; logo, o reconhecimento do direito não é suficiente para a promoção da justiça social e muito menos esta é conseguida por meio de discriminações positivas, dado o seu caráter excludente e negador do direito universal. 
A esse respeito, a universidade tem sido objeto de distintas discussões, apresentando posicionamentos pretensamente morais diversos, incluindo aqueles que insistem que o processo de expropriação histórica é mais cultural do que socioeconômico, sem se ater na totalidade da relação capital-trabalho que efetivamente promove a manutenção do arranjo histórico do sistema capitalista, mesmo em face de um discurso que afirme o contrário. Qual seria o caminho? Qual é a possibilidade efetiva de transformação social para pensarmos e vivermos a realidade da não exclusão ou o direito da cidadania em seu sentido mais amplo?

O primeiro e necessário encaminhamento a essas questões centra-se na recuperação do sentido entre direito, democracia, universalização e humanização como objetos inalienáveis da história e condição material humana e que não se dará de forma gratuita ou naturalmente, mas por meio da manifestação do homem que se mobiliza na história e com a história.

Habermas (2003a, p. 13), por sua vez, aponta que as populações de forma geral sentem a fragilidade das instituições ditas democráticas e não as concebem totalmente como representantes de sua liberdade ou direito em sentido pleno, ou seja, não mais são consideradas como inatacáveis. A sua conclusão, ou "suposição", em suas palavras, é a de que essa inquietação deriva de uma razão muito mais profunda, quer seja, “[...] o pressentimento de que, numa época de política secularizada, não se pode ter nem manter um Estado de direito sem democracia radical."

Certamente a democracia radical é uma necessidade frente ao panorama pusilânime do sistema capitalista; entretanto, o apontamento de sua necessidade não se atrela simplesmente a uma projeção do que está para acontecer, como é o caso da suposição de "pressentimentos", mas advém daqueles que tiveram e têm a sua existência expropriada, da leitura daqueles que tiveram o seu direito negado e das reivindicações sociais da necessidade de uma outra democracia.

A democracia radical em Habermas (2003a, p. 21-22) centra-se na razão ou agir comunicativo do direito, na qual não mais a razão prática dos interesses de mercado predomina, mas "uma orientação na base de pretensões de validade", ou seja, "[...] abrange todo o espectro de pretensões de validade da verdade proposicional, da veracidade subjetiva e da correção normativa, indo além do âmbito exclusivamente moral e prático." A sua perspectiva é a de que numa democracia radical, considerando o direito cidadão, o ponto de partida é a força integradora de processos de entendimentos não violentos, pois esses são capazes de recuperar e respeitar as distâncias e diferenças reconhecidas, a partir de uma "[...] base da manutenção de uma comunhão de convicções".

Em se tratando das políticas sociais de inclusão na universidade, certamente o aparato jurídico, embora ressalte as suas regulamentações, é muito frágil, uma vez que centrado em princípios normativistas, afasta-se do mundo da vida, isto é, 
do agir comunicativo, centro da vida social. Assim particulariza sua orientação e reifica os parâmetros do aparelho estatal de base neoliberal.

A argumentação de que vivemos numa época de solidariedade planetária e de que os processos de inclusão social, como normas jurídicas, representam o melhor panorama para promover o direito a quem de direito o tem, segundo a linha de raciocínio que estamos desenvolvendo, não tem sustentação, pois as concessões apenas aparentam a legitimidade de justiça social, referendam os imperativos organizacionais do direito determinado à luz da lógica das classes hegemônicas.

Como enfatiza Habermas (2003b), a justiça social em seu sentido indistinto é deslocada para o âmbito da retórica, prevalecendo um desvio conceitual de equidade e, portanto, do alcance do direito a ter direitos. É possível uma dimensão de equidade dualista, forjada em conformidade com as desigualdades sociais e com a divisão internacional do trabalho? Não, assim como não é admissível que o ingresso à universidade pelas classes desfavorecidas se dê pela outorga de uma concessão normativa restritiva a uma percentagem, ao esvaziamento do Estado na proposição de Educação Superior universalizada e à manutenção de um sistema dualista de educação.

O agir comunicativo do direito na determinação da ação histórica, na perspectiva de Habermas (2003a, 2003b), destaca que não pode e nem deve haver dualidade na universalização da justiça porque essa valida o mundo vivido, assegurando a integração social, em seu sentido amplo e restrito, não por motivações particularistas de seus destinatários, mas pelas exigências mais amplas das convenções assumidas da vida em sociedade. Se o dualismo se manifestar de forma explícita ou implícita, "A circulação comunicacional do mundo da vida é interrompida no ponto onde se choca com o dinheiro e o poder administrativo, meios que são surdos às mensagens da linguagem coloquial [...]" (HABERMAS, 2003a, p.82).

É nesse último estágio que podemos identificar a sociedade atual e suas políticas públicas elaboradas segundo uma ordem jurídica, política e econômica particularista, a partir de cópias do desenho do mercado capitalista internacional e suas agências de financiamento multilaterais, cujo discurso apresenta consistência na defesa de direitos e oportunidades universais. Tanto é que até muitos acadêmicos se dão por convencidos disso, quando concretamente a roteirização das premissas do metabolismo do capital coopta e desmobiliza as articulações que se esmeram pela emancipação do homem e pela transformação social.

As ações afirmativas para ingresso à universidade brasileira seguem esse parâmetro, ferindo em todos os graus o princípio do direito à igualdade e à justiça social, ao propor simulacros especiais e temporários, tornando um recorte da sociedade "mais igual" do que o outro. Diz Hobsbawn (2002, p. 562) que o 
futuro não pode ser a continuidade do passado ou do presente, há que se buscar o sentido da democracia radical na superação do sistema capitalista, pois "sabemos que, por trás da opaca nuvem de nossa ignorância e da incerteza de resultados detalhados, as forças históricas que moldaram o século continuam a operar".

A anuência às proposições paliativas do alcance gradual ao direito atesta que, embora tenhamos a consciência do processo de expropriação, estamos embalados por ditosas orientações ideológicas. Acerca dessa disposição Hobsbawn (2002, p. 562) conclui que

[...] uma coisa é clara. Se a humanidade quer ter um futuro reconhecível, não pode ser pelo prolongamento do passado ou do presente. Se tentarmos construir o terceiro milênio nessa base, vamos fracassar. E o preço do fracasso, ou seja, a alternativa para uma mudança da sociedade, é a escuridão.

\section{A universidade e o antagonismo entre o particular e o universal a partir de Adorno e Horkheimer}

Uma visão pontuada pelo olhar crítico sobre o fenômeno histórico-social não pode ser dissociada do antagonismo existente entre os interesses particulares e os universais em todo o tecido social, no qual o particular é "naturalizado" como universal e o universal proposto como meio para o fortalecimento do ideário hegemônico, portanto, particular.

Um exemplo oportuno, no caso desse ensaio, são as ações afirmativas como meio de acesso para as classes desfavorecidas à universidade, que como um dos instrumentos do metabolismo do capital, não tem como meta a proposta da oferta de Educação Superior pública e de qualidade para todos. Muito embora discursivamente defenda essa perspectiva, a sua orientação é outra, isto é, para a ressignificação do âmbito de "público" e "accountability" (responsabilização social) difusa nos âmbitos deontológicos e axiológicos, reunindo o mundo em torno do que denominam de esforço e solidariedade universais para um mundo melhor.

Não se trata de conferir a "todos" a oportunização de Educação Superior, mas, ao conter o caráter reivindicatório da universidade pública, gratuita e de qualidade, conceituada convenientemente de "público-estatal", enfatiza a inclusão educacional pelo "público não estatal" como único e possível caminho 
que poderá elevar, por sua eficiência e competência de mercado, o nível social dos assistidos.

Tais conjuntos ideológicos, em sentido restrito (e que não os explicitam propositalmente), são facilmente incorporados pelo próprio Estado que transfere "verbas" para o setor privado do ensino superior (em grande medida, "responsabilizado" por "acolher e cuidar" dos interesses centrais da nação na inserção de classes menos favorecidas às oportunidades sociais).

A ênfase do setor privado, por sua vez, é a da expansão das oportunidades sociais, por manifestações diversas de ações afirmativas, pois defendem que há, ainda, muitos cidadãos (clientes) "fora do sistema", que por meio de políticas públicas de subvenção poderiam ser contemplados na relação de parceria publico-privada, tendo a partida do governo e a contrapartida do setor privado como orientação solidária.

Observamos que não mais se advoga a necessidade de transformação social em sua manifestação mais radical porque se diz que já estamos vivendo essa fase, que há aquiescência e mobilização de inúmeros setores sociais quanto a essa lógica desenvolvida, inclusive de dentro da própria universidade nos posicionamentos sinergéticos, dispostos a justificar a necessidade das ações afirmativas e da "responsabilidade de todos" e de "cada um" para a realidade nacional, além é claro de rotular os contrários como alienados e reduzir qualquer terceiro olhar à categoria de inconsistência teórico-prática. Não há dúvida de que o pensamento particularizado ascendeu ao status de universalizado, pelo convencimento, confusão e partidarismo.

Assim, a partir de um olhar crítico-reflexivo, não há possibilidade de considerarmos a inclusão educacional, por meio das ações afirmativas, simplesmente como uma questão de opção ou da chamada "consciência social" em nome dos valores humanos e das reparações compensatórias historicamente situadas (dimensão particularizada), mesmo que e inclusive por meio de modelos internacionais sem considerar a necessidade de uma ruptura radical com a lógica do capital.

Qualquer posicionamento no âmbito naturalizado de inclusão sem o ser de fato (entendendo que a inclusão como interesse particular não erradica a exclusão) concorre para a negação de uma dimensão mais ampla das " [...] mudanças educacionais comprometidas com a emancipação dos sujeitos sociais e com a construção de sociedades mais justas e igualitárias...” (PESCE, 2007, p. 17).

A necessidade da reversão de um quadro ideológico, mantenedor da hegemonia social e econômica, para Adorno e Horkheimer (1973), deve ser pauta objetiva de um esclarecimento novo, não mais concebido segundo as "leis naturais da produção capitalista", a que chama de dialética do esclarecimento. 
Nesse âmbito, Adorno e Horkheimer (1985) apontam que o verdadeiro esclarecimento não mais pode ser entendido numa ingênua perspectiva mítica entre o "bem" e o "mal" ou entre o "mal menor" e o "mal maior", mas como base para tirar o homem de seu processo de alienação ou de sua menoridade e não mais ser conduzido, mas conduzir a construção de sua própria história.

Por isso, a naturalização do momento histórico solidário das ações afirmativas refracionado pela defesa da inclusão educacional à universidade brasileira deve ser colocada em suspensão, pois, inclusive por meio de "leis reguladoras", suas finalidades originais são manifestas, isto é, os interesses particulares dos grupos sociais hegemônicos são defendidos como síntese dos interesses gerais ou universalizados de toda a sociedade, não havendo mudanças substantivas na estrutura da teoria social que as condiciona.

Adorno e Horkheimer (1973, p. 35) afirmavam que "as leis históricas de determinada fase não constituem simples modos de manifestação de leis mais gerais, mas, pelo contrário, todas as leis são instrumentos conceptuais criados com a finalidade de dominar as tensões sociais em suas origens teóricas".

Em relação à particularização da justiça em detrimento da universalização da equidade, tomando as ações afirmativas como ponto de análise, podemos afirmar que a aceitação tácita de sua proposição particulariza e condiciona uma tipologia de sociedade (de caráter mítico) negligenciando, consequente e convenientemente, a universalização social de oportunidades. Dessa forma, o abismo entre o particular e o universal permanece, restando a ilusão de horizontalidade.

Defende-se que a solidariedade entre os povos e a comunhão dos benefícios da humanidade fazem parte de uma realidade objetiva e, portanto, enviam esforços a partir das necessidades objetivas, incluindo-se o acesso aos níveis mais elevados da educação. Assim, no projeto de sociedade atual, conseguir-se-á concluir a superação das desigualdades sociais; entretanto, alertam Adorno e Horkheimer (1985, p. 48):

Os próprios dominadores não acreditam em nenhuma necessidade objetiva, mesmo que às vezes dêem esses nomes às suas maquinações. Eles se arvoram em engenheiros da história universal. Só os dominados aceitam como necessidade intangível o processo que, a cada decreto elevando o nível da vida, aumenta o grau de sua impotência.

O antagonismo entre o particular e o universal no arranjo da sociedade anunciada e vivida como um jargão vencido, considerando as "conquistas" atingidas e estendidas para toda a sociedade, é linguagem corrente, situan- 
do-o como uma ideologia reducionista. A indústria da dominação conforma tal "esclarecimento" como definitivo e irrevogável, dado o estado necessário de sinergia social, mas a ideologia predominante é a particularista, metamorfoseada de universal.

O despertamento dessa realidade se dará pela dialética de um esclarecimento não forjado, que possibilite ao homem como ser histórico a não aceitação da imediatez de medidas consentidas, impingidoras de impotência naturalizada num mundo determinado e esgotado de alternativas.

A compreensão da universidade sob a dialética do esclarecimento problematiza a análise linear e planificada de benefícios ideais consentidos ou mesmo de políticas públicas à luz de uma teoria social que reforça a estrutura do capitalismo. A sua ênfase central é a de que as lutas e construções históricas conferem ao homem a necessária autonomia para a leitura da realidade, articulando individualidade e universalismo e não individualismo e universalização em sentido restrito.

\section{A universidade e a dialética do concreto a partir de Karel Kosik}

Entender e encaminhar a universalização, democratização e humanização do homem que elabora o seu conhecimento histórico e que se autoproduz é a grande necessidade para tornar a sociedade e, portanto, as instituições sociais em geral num espaço comum, sem exclusão, como por exemplo na universidade. É oportuno destacar que a leitura do mundo vivido por meio de sua materialidade não acontece no vazio, muito embora o sistema queira determinar o seu sentido abstrato, externando apenas a face que lhe é conveniente desse mundo, ao que Kosik chama de pseudoconcreticidade.

Uma vez desdobrada a perspectiva da dialética do esclarecimento que se fundamenta no despertamento para uma leitura crítica do mundo, encontramos na Dialética do Concreto de Karel Kosik (1976) a recorrência do mundo concreto e a denúncia da pseudoconcreticidade, elementos fundamentais para problematizarmos o contexto da Educação Superior consentida no Brasil por meio de ações afirmativas.

A realidade educacional brasileira não é fruto de mera intuição, determinada por aportes teóricos ou de uma práxis utilitarista (por isso a disposição do desenvolvimento de medidas de inclusão social pontuais), antes é manifestada e condicionada por múltiplas determinações e interesses de classe. 
Exatamente por isso é que não é admissível pensar as ações afirmativas como respostas finais sobre o acesso dos grupos desfavorecidos à universidade, como se qualquer outro caminho não existisse, como se essas fossem suficientes para resolver as problemáticas de exclusões naturalizadas - caminho da pseudoconcreticidade que, com a sua regularidade, imediatismo e evidência, penetra nas consciências dos indivíduos, assumindo um aspecto independente e natural. Kosik (1976, p. 11) reúne quatro pontos que caracterizam sua fundamentação:

a) O mundo dos fenômenos externos, que se desenvolvem à superfície dos processos realmente essenciais, em que as políticas públicas de ações afirmativas desenvolvidas pelo Estado brasileiro têm efeito e caráter remediativos, conforme as disposições das tensões sociais, marginalizando as questões sociopolíticas de fundo, mais afinadas com o mercado internacional do que com a universalização de oportunidades propriamente ditas;

b) O mundo do tráfico e da manipulação, isto é, da práxis fetichizada dos homens (a qual não coincide com a práxis crítica revolucionária da humanidade), configurando-se no rol da condução dos interesses ideológicos, em que o anúncio abstrato de um mundo solidário entorpece pelo convencimento o pensamento crítico, por meio de encontros sazonais promovidos por entidades multilaterais, pela divulgação de experiências exitosas da eficiência e eficácia do sistema capitalista aplicadas à educação e na projeção de um mundo de paz e igualdade social;

c) O mundo das representações comuns, que são projeções dos fenômenos externos na consciência dos homens, produto da práxis fetichizada, formas ideológicas de seu movimento, no qual, em relação à universidade brasileira, suas reformas e adesão ao ideário da divisão internacional do trabalho, é correto afirmar que há uma intensa mobilização política, advinda de setores hegemônicos para que se iguale ou assemelhe o mais possível aos modelos concertados pela UNESCO e outras agências de financiamento internacionais, a exemplo do que fazem outros países em desenvolvimento;

d) O mundo dos objetos fixados, que dão a impressão de ser condições naturais e não são imediatamente reconhecíveis como resultados da atividade social dos homens, em que as políticas públicas e as de ações afirmativas em particular apresentam disposições ambíguas como respostas para a consertação das desigualdades sociais. A outorgação do "privilégio" ao ensino superior, recebida consensualmente, não é resultante dos encaminhamentos democráticos de direito, excluindo o próprio homem do âmbito emancipatório, humanizador e universal, por conta da ignorância de sua ação social. 
Segundo Kosik (1976), é necessário destruir a pseudoconcreticidade para que a realidade se mostre por meio de uma práxis emancipatória, à luz do pensamento dialético. Esse caminho metodológico não linear elimina os desvios e elementos ocultadores de quaisquer interesses particularistas, tendo como cerne a reapropriação da leitura do mundo concreto, bem como os encaminhamentos necessários para a consecução de uma sociedade equitativa.

Por isso é possível pensar a universidade para além das ações afirmativas, pela não redução da consciência às condições dadas e pela descoberta e redescoberta da práxis humana, do sentido de sua produção na história e vice-versa.

O motivo pelo qual se justifica a presença de ações paliativas para o acesso à universidade no Brasil não explicita a necessidade de mudança da teoria social que fundamenta o sistema capitalista, ao contrário, naturaliza-o ao ponto de, além de considerar os arranjos necessários para a sua manutenção, condiciona as medidas outorgadas à responsabilização da iniciativa privada como benfeitoras imprescindíveis ao processo de inclusão social ou discriminação positiva, como no caso europeu. Admite-se com isso a incontrolabilidade da "mão invisível" do capital como controladora, mas, "[...] generosamente benevolente para os capitalistas particulares e ao mesmo tempo para toda a sociedade" (MÉSZÁROS, 2006b, p. 137).

O mundo da pseudoconcretidade, isto é, do afastamento da leitura correta que deveria desenvolver as mobilizações para uma transformação social efetiva, sem dúvida alguma é cada vez mais reforçado, encampando fileiras de favoráveis que aderem ao primado de que o processo de integração social é possível pela mudança cultural e capacidade solidária de transcendência da pobreza. Esses postulados não têm sustentação quando a concreticidade se manifesta na descoberta do homem como tal e do mundo como produto de múltiplas manifestações materiais e por isso mesmo suscetível de ser transformado; logo, as medidas paliativas frente às tensões sociais são instrumentos de resistência convenientemente utilizados para a conservação da teoria social do capitalismo.

\section{A universidade e as práticas dissimuladoras na centralidade capital- -trabalho a partir de Mészáros}

A geração das desigualdades, da fome, do desemprego e dos preconceitos são temas amplamente discutidos na sociedade mundial como fatores agravantes do desenvolvimento econômico, subtraindo possibilidades de redistribuição de renda e a promoção da justiça social. Nessa direção, não é possível ignorar a 
discussão de ações afirmativas para as classes desfavorecidas como meio de inclusão educacional à universidade brasileira alienada das práticas dissimuladoras na centralidade capital-trabalho.

Dentre outras, essas políticas públicas declaram que não há outra alternativa, em nível mundial, para o encaminhamento da equidade no campo educacional. Assim, com o "fim da história" ou com a sinergia dos governos mundiais, ocorre a inclusão de mais pessoas e instituições, implicando a responsabilização de todos e de cada um e com isso a oportunização com justiça social.

A aceitação do sociometabolismo do capital permanente e universal, condicionada por ideologismos reiterados, ascendem a um âmbito cada vez maior, ao ponto de os movimentos sociais e a sociedade como um todo chegarem à conclusão de que

É bem mais fácil resignar-se à irreversibilidade do dilema afirmada no determinismo cego deste slogan político de nosso tempo - sem sequer tentar uma avaliação, muito menos um questionamento, de suas seríssimas implicações - do que imaginar a forma de enfrentá-lo. (MÉSZÁROS, 2006b, p. 37).

A universidade brasileira como uma das instituições históricas de formação de elites, além de não fugir a essa lógica, a naturaliza por sua passividade e incorpora o ideário do capital e do capitalismo ${ }^{2}$ à sua missão, visão e ação: igualdades de oportunidades sociais, contraditoriamente, enquanto o Estado capitalista assegura os privilégios da educação, dentre outros, para a classe hegemônica, mitologiza a igualdade para os trabalhadores e conserva o coração do sistema sob o compasso da desigualdade.

2 Antunes (2002), a partir de Mészáros (2005), lembra que: "Como um dos eixos centrais de sua interpretação particular do fenômeno, Mészáros considera capital e capitalismo como fenômenos distintos. A identificação conceitual entre ambos fez com que todas as experiências revolucionárias vivenciadas no século passado, desde a Revolução Russa até as tentativas mais recentes de constituição societal socialista, se revelassem incapacitadas para superar o "sistema de sociometabolismo do capital", isto é, o complexo caracterizado pela divisão hierárquica do trabalho, que subordina suas funções vitais ao capital. O capital antecede ao capitalismo e é a ele também posterior. O capitalismo, por sua vez, é uma das formas possíveis de realização do capital, uma de suas variantes históricas, como ocorre na fase caracterizada pela subsunção real do trabalho ao capital. Assim como existia capital antes da generalização do sistema produtor de mercadorias, do mesmo modo pode-se presenciar a continuidade do capital após o capitalismo, pela constituição daquilo que Mészáros denomina como "sistema de capital pós-capitalista", que teve vigência na URSS e demais países do Leste Europeu, durante várias décadas do século XX” (grifo nosso). 
As mudanças substantivas para uma universidade não excludente em nível de dimensão democrática, humanizadora e universal são praticamente inviáveis porque desqualificadas pela teoria social do capital, restando como caminho "incontornável" e "incorrigível" as políticas públicas paliativas, como as de ações afirmativas.

Quando das proposições advindas do sociometabolismo do capital por meio de uma indústria cultural ${ }^{3}$ forjada em relação à inclusão educacional, percebe-se nitidamente que não existe grau de isenção sobre sua intencionalidade, isto é, "a plausibilidade e a influência espontânea do discurso ideológico dominante, influência essa que atinge muito além das fileiras de seus verdadeiros beneficiários, residem precisamente em seu apelo tranqüilizador à 'unidade' e às preocupações a elas associadas [...]” (MÉSZÁROS, 2004, p. 328). A ideologia em sentido restrito traveste-se na incorporação de atendimento às necessidades das demandas, "[...] no assistencialismo e nas políticas compensatórias, sem caminhar absolutamente nada na distribuição das riquezas socialmente produzidas" (SANFELICE, 2006, p. 37).

Portanto, o que vale é o controle das tensões sociais por meio de medidas inclusivas e "paliativas", tendo em vista a consecução do ideário neoliberal, e sabendo-se que a educação é o instrumento mais eficaz para a interiorização do mundo naturalizado e como diz o próprio Mészáros (2005, p. 45), a educação desenvolvida na lógica do capital consegue "[...] produzir tanta conformidade ou 'consenso' quanto for capaz, a partir de dentro e por meio dos seus próprios limites institucionalizados e legalmente sancionados", mas pode produzir uma leitura para a emancipação também.

\section{Considerações finais}

Ao considerarmos o crescimento das prescrições dos organismos multilaterais ao Estado sob a égide da Terceira Via e a adesão às ações afirmativas na universidade brasileira, podemos constatar que, embora a ideologia hegemônica veicule propostas para a inclusão educacional e encontre respaldo, por conta de

3 Para Pesce (2007, p. 14), a “[...] indústria cultural intenciona explicitar o caráter de mercadoria auferido à cultura contemporânea. Nessa perspectiva, promove diversas reduções, dentre as quais destacamos: o saber, à mercadoria; a cultura, à semicultura; a individualidade, à pseudo-individuação. Por tudo isso, a indústria cultural consubstancia-se como meio de adaptação das massas ao sistema dominante, travestido em indústria da diversão". O mesmo acontece em relação aos valores que pretende defender e ou ratificar. 
democratização, humanização e universalização, os seus limites são estruturais e, como observa Sanfelice (2006), consequentemente não promotores de qualquer mudança que desvie ou modifique a teoria social que a sustenta: o neoliberalismo.

Os limites estruturais do capital são frágeis e isso explica tanto empenho e intensivo planejamento para o condicionamento do mundo sob essa perspectiva, que, por sua vez, explica o porquê da permanência como desafio e fardo no tempo histórico. Por conta de estratagemas e amplíssimo arsenal ideológico da internacionalização do capital, codinomizado em seu conjunto de "terceira via" como solução aos problemas políticos e sociais dos países desenvolvidos e em desenvolvimento, tem havido "[...] aceitação submissa da ordem dominante" desmobilizando intelectuais, acadêmicos e movimentos radicais de massa por meio de uma moeda falsa, impotente de promover ou gestar a universalização da justiça social (MÉSZÁROS, 2007, p. 132).

A leitura de mundo apresentada pelo ideário capitalista ou neoliberal distancia-se do questionamento dos antagonismos estruturais do próprio sistema ou, quando o faz, propõe, sustenta e dissemina a estrutura racional de seu mundo real e em havendo desafetos explícitos de ordem macro ou microssocial, pelo primado da separação dos efeitos e causas, justifica o tratamento sobre os efeitos do sistema, isto é políticas públicas situacionais, ao invés de, a partir das causas, trabalhar-se políticas públicas estruturais.

Qual a alternativa, portanto, para a transformação social e especificamente para a universidade no Brasil numa dimensão universal, democrática e humanizadora distanciada da estratégia reformista do sistema capitalista, corporificada pelos países em desenvolvimento pela reforma do Estado?

O reformismo capitalista não pleiteia e, de fato, nunca pleiteou diretamente a solução real de problemas sociais. Postula sim a mudança gradativa da sociedade por meio da remoção ou do encaminhamento de "defeitos específicos" como sistema alternativo às tensões socialmente mais visíveis. Assim, seria

[...] a rejeição apriorística das chamadas grandes narratives em nome de petits récits. Idealizadas arbitrariamente - é na realidade apenas uma forma peculiar de rejeitar, sem uma análise adequada, a possibilidade de ter qualquer sistema rival, e uma forma igualmente apriorística de eternizar o sistema capitalista (MÉSZÁROS, 2005, p. 63, grifo nosso).

Com isso não se resolve o problema da exclusão social ou educacional, mas o desmantelamento e o desarranjo da perspectiva de mudança da estrutura social permanece, inclusive na universidade por meio das ações (afirmativas) 
consentidas, ratificadoras da educação dualista histórica no Brasil e no mundo: a produção de mão de obra qualificada para o mercado, por um lado, e das elites dirigentes de outro.

Consequentemente, indivíduo e sociedade são alijados de sua realização social e humana não transcendendo, de fato, à alienação produzida pelo sistema. Temos aqui uma perspectiva significativa de que qualquer alienação social não deve ser tratada como um "defeito específico", e se defeito, há que se pensar em suas causas geradoras em nível macrossocial, há que se pensar que, para a realização do indivíduo do ponto de vista humano, devemos reivindicar uma educação com uma estrutura social distinta do ideário neoliberal, no caso de acesso à universidade no Brasil, de maneira a apropriar-nos da justiça social concreta.

O caminho para a emancipação da educação e oportunidades educacionais, inclusive na universidade, centra-se no rompimento com a lógica capitalista na universalização da educação e trabalho como atividade humana autorrealizadora. Nesse encaminhamento concluímos com Mészáros (2005, p. 27) que limitar "[...] uma mudança educacional radical às margens corretivas interesseiras do capital significa abandonar de uma só vez, conscientemente ou não, o objetivo de uma transformação social qualitativa".

As políticas públicas preocupadas em "sanar" defeitos específicos do próprio sistema, inclusive por meio de ações afirmativas à universidade brasileira, não o farão, uma vez que, "remendar aqui e ali" só reforça o controle do sistema capitalista historicamente situado, favorecendo ideologicamente a sua continuidade. A reversão dessa realidade, entretanto, não reside somente no esclarecimento ideológico ou político, marginalizando a sua dimensão prática, pois "só é possível um êxito duradouro por meio da mobilização sustentada, de forma organizada, das grandes massas para a realização de uma alternativa hegemônica abrangente ao modo de reprodução sociometabólica existente" (MÉSZÁROS, 2009 , p. 108), justamente o sentido oposto da alternativa conformadora e excludente radicada e em nome da justiça social. Apesar de Mészáros não falar especificamente sobre inclusão na educação, convida a todos os anuentes à lógica capitalista a reivindicarem uma educação democrática, humanizadora e universal, recuperando o sentido de democratização em todas as suas esferas.

\section{REFERÊNCIAS}

ADORNO, T. W.; HORKHEIMER, M. Dialética do esclarecimento. Rio de Janeiro: Jorge Zahar Editor, 1985. 
. Temas básicos da sociologia. São Paulo: Cultrix, 1973.

ANDERSON, Perry. Balanço do neoliberalismo. In: SADER, Emir; GENTILI, Pablo. Pós-neoliberalimo: as políticas sociais e o Estado democrático. Rio de Janeiro: Paz e Terra, 2000.

ANTUNES, Ricardo. A desertificação neoliberal no Brasil: Collor, FHC e Lula. Campinas, SP: Autores Associados, 2004.

. Para além do capital e de sua lógica destrutiva. Revista Espaço Acadêmico, ano II, n. 14, jul. 2002.

HABERMAS, Jürgen. A inclusão do outro: estudos de teoria política. São Paulo: Edições Loyola, 2007.

. Direito e democracia: entre facticidade e validade. v. I. Rio de Janeiro: Tempo Brasileiro, 2003a.

Direito e democracia: entre facticidade e validade. v. II. Rio de Janeiro: Tempo Brasileiro, 2003b.

HOBSBAWN, Eric J. A era dos extremos: o breve século XX. São Paulo: Companhia das Letras, 2002.

KOSIK, Karel. Dialética do concreto. 2. ed. Rio de Janeiro: Paz e Terra, 1976.

LIMA, Paulo Gomes. Unha de gato em novelo de lã ou do financiamento da pesquisa científica \& tecnológica no Brasil no governo Fernando Henrique Cardoso (1994-2002): o dito e o feito no "plano real". Tese (Doutorado em Educação Escolar) - Universidade Estadual Paulista Julio de Mesquita Filho - FCLAR/UNESP, Araraquara/SP, 2005.

MARX, K; ENGELS, F. Manifesto do Partido Comunista. In: Conjunto de autores. $O$ Manifesto comunista 150 anos depois. Rio de Janeiro-São Paulo: Contraponto: Fundação Perseu Abramo, 1998.

. A ideologia alemã (Feuerbach). 6. ed. Trad. de José Carlos Bruni \& Marco Aurélio Nogueira. São Paulo: Hucitec, 1987.

MÉSZÁROS, Istvan. O poder da ideologia. São Paulo: Boitempo Editorial, 2004. . A educação para além do capital. São Paulo: Boitempo Editorial, 2005. . A teoria da alienação em Marx. São Paulo: Boitempo Editorial, 2006a. . Para além do capital. São Paulo: Boitempo Editorial, 2006b. . O desafio e o fardo do tempo histórico. São Paulo: Boitempo Editorial, 2007. . A crise estrutural do capital. São Paulo: Boitempo Editorial, 2009.

PESCE, Lucila. As contradições da institucionalização da educação a distância, pelo Estado, nas políticas de formação de educadores: resistência e superação. Departamento de Filosofia e História da Educação - Programa de Pós-graduação da Faculdade de 
Educação. Relatório final de pesquisa de Pós-Doutoramento. Universidade Estadual de Campinas, 2007.

SANFELICE, José Luis. Inclusão educacional no Brasil: limites e possibilidades. Revista de Educação da PUC-CAMPINAS, n. 21, p. 29-40, nov. 2006.

Texto recebido em 21 de julho de 2013. Texto aprovado em 18 de dezembro de 2013. 